\title{
Pension Funding in a Unionized Economy
}

\author{
Antonis Adam* \\ (DIEES, AUEB)
}

\begin{abstract}
This paper analyzes the effects of a move to a funded pension system in a small unionized economy. Using an overlapping- generations framework we show that a reform towards a funded pension system may result in lower levels steady state of employment and capital stock. Moreover we show that the possibility of a Pareto improving transition to a funded system hinges on the employment effects of the reform- with a rise in employment guarantying a Pareto improving transition.
\end{abstract}

JEL Classification: H55, J51, J32

Key words: public pensions, labour union, unemployment

\footnotetext{
* Correspondence: Athens University of Economics and Business, Department of International and European Economic Studies, 76 Patission st., 10434, Athens, Greece Tel:+30-210-8203354; fax:+30210-8214122

E-mail address: $\underline{\text { aadam@aueb.gr }}$

Acknowledgments: I wish to thank Thomas Moutos, Panos Hatzipanayotou, James McHugh, Spyros Vassilakis for helpful comments and discussions. The research presented in this paper was financially supported by the Greek Ministry of Education and the European Union under the "Iraklitos" research fellowship program.
} 


\section{Introduction}

The presence of high unemployment is usually considered detrimental to the viability of public pension systems. Yet what may seem as a challenge to some, to others represents an opportunity; Corneo and Marquardt (2000) and Demmel and Keuschnigg (2000) have argued that in an imperfectly competitive market, characterized by the presence of unemployment creating labour unions, a move towards a funded system can be Pareto improving ${ }^{1}$; when the returns to the PAYGO system are lower than the returns of comparable investment in the capital market, Pay- As- YouGo (PAYGO) contributions constitute an implicit tax on labour. A reduction on the (implicit) tax on labour reduces unemployment, thereby generating efficiency gains which may be exploited in order to design a Pareto improving transition policy to a funded system. The above finding is in line with the literature on the transition to a funded system when labour supply is endogenous (Breyer, 1989, Homburg, 1990).

This paper extends the above analyses by considering non- myopic labour unions (i.e. unions that maximize the intertemporal utility of their members) and taking into account that the PAYGO benefit redistributes income both within the same generation and also between generations. Incorporating these elements into our analysis implies that the PAYGO system induces labour unions into showing wage moderation.

This is because PAYGO pensions are financed by a tax on labour income, i.e. higher income workers pay higher taxes, whereas benefits are redistributive in the sense that they do not utterly depend on the contributions of the individual worker. For a single union, wage increases are less valuable as they only increase the working period income, without (fully) affecting post- retirement income; and still they come at the

\footnotetext{
${ }^{1}$ The has been a vast literature highlighting the benefits and the efficiency gains from moving to a private fully funded pension system, see for example World Bank (1994), Diamond (1996), Gramlich (1996), Holzman (1997) and Feldstein and Liebman (2002) for a survey.
} 
cost of higher unemployment. Then the equilibrium effect of a cut in the publicPAYGO pension scheme will depend on two opposing effects: the first arising from the cut on the implicit labour tax (as in Corneo and Marquardt, 2000 and Demmel and Keuschnigg, 2000), which reduces unemployment and the other from the wage moderating effect of the PAYGO pension, which increases unemployment. The net effect of these two forces on the unemployment rate is ambiguous a- priori, but we show that it depends on the degree of redistribution of the PAYGO system and on the difference between the rate of growth of the economy and the rate of return of the capital market, i.e. the level of the implicit labour tax.

When one discusses however the possibility of reform from a PAYGO to a funded pension system, the issue of the transition should be addressed. When switching to a funded system, the members of the young generation must provide their own retirement benefits and also contribute to the servicing of the pension obligations to the elderly. The transition to the funded system then can be Pareto optimal only when the present value of all efficiency gains of the reform are greater than the pension obligations at the timing of the transition. The model presented here shows that if the cut in the PAYGO benefit is unemployment reducing, i.e. the gain from the reduction in the implicit labour tax is higher than the loss of the wage moderating effect of the PAYGO system, then a Pareto improving reform can be designed, using a simple public debt policy. However if the cut in the PAYGO benefit is unemployment creating, then the cost of the reform will always be greater than the present values of the gains, and for some parameter values the gains may be negative.

The rest of the paper is structured as follows: in the next section we describe the model. In section 3 we show the effects of increased pension funding on the macroeconomic equilibrium of the economy. Section 4 examines the welfare effects of 
increased pension funding and the issue of transition to a funded system. Finally section 5 concludes.

\section{The Model}

The model presented is a variant of Deveraux and Lockwood (1991) trade union model. We consider an overlapping generations model of a small open economy with free capital mobility, perfect foresight and discrete time $t=1,2, \ldots, \infty$. A large number of perfectly competitive, identical firms produce a homogeneous tradable good under decreasing returns to scale, with the use of capital and labour. The small open economy assumption implies that both the interest rate and the price of the good are determined in the world market and thus given to the domestic economy.

At each time period t the economy is populated by two generations of identical

individuals, the young and the old. The ratio of young to old individuals, $\frac{N_{t}}{N_{t-1}}$, is $(1+n)$. All individuals live for two periods and are endowed with one unit of labour which they supply inelastically in the first period of their life; they are also members of a firm specific labour union. We assume that the equilibrium in the labour market is determined by (firm level) bargaining between the union and the firm. As a consequence, in equilibrium, wages are higher than full employment wages and there is unemployment in the model. Old individuals receive a pension benefit as long as they had been employed, and had made contributions to the system when they were young. The retired individuals consume all their income and do not leave any bequests.

Finally the government levies taxes on the income of the employed in order to finance two social security benefits: old age- pension and unemployment benefits. 


\section{Consumers- Workers}

Consumers- workers are risk neutral and derive utility from a well behaved utility function, defined over consumption when young and old. In order to derive analytical solutions we assume that the utility function is Cobb- Douglas:

$$
U=c_{t}^{\delta} c_{t+1}^{1-\delta}
$$

where $c_{t}$ and $c_{t+1}$ are first and second period consumption respectively and $\delta(<1)$ is the relative weight of the first period consumption.

Employed workers earn a net of taxes wage rate $\mathrm{w}_{t}(1-\tau)$. The wage tax rate $\tau$ consists of contributions $\xi$ to the unemployment insurance and contributions $\mathrm{z}$ to the pension program, such that $\tau=\xi+z$. When unemployed, individuals receive an unemployment benefit which is proportional to the average economy- wide wage rate ${ }^{2}$. If we define $\mathrm{b}$ as the unemployment replacement ratio and $\bar{w}_{t}$ the economy wide average wage rate at $t$, then the unemployment benefit will be equal to $b \bar{w}_{t}$. We impose the additional assumption that $\mathrm{b}$ is lower than $1-\tau$ so that in equilibrium all individuals prefer being employed rather than unemployed. Furthermore we assume that the income of the unemployed is not taxed. Finally when old, all those that have contributed to the system, i.e. individuals that were employed when they were young, are entitled to receive a pension benefit ${ }^{3} \mathrm{P}_{\mathrm{t}+1}$. For the time being we assume that the level of the pension benefit is not affected by the consumption- saving decision of the

\footnotetext{
${ }^{2}$ By assuming that the unemployment compensation is proportional to the wage rate we can solve analytically for the equilibrium unemployment (see equation (21)). Our main argument carries through even if we assume that the unemployment benefit is not proportional to the wage rate or that the unemployed have a fully exogenously given outside option, however in this case we cannot solve analytically for the level of employment and wages. Yet the numerical solution with an exogenously outside option is almost identical to the one presented in the text, i.e. with an unemployment benefit proportional to the wage rate.

${ }^{3}$ Here we have assumed that only those that have contributed to the pension system are entitled to pension benefits. Alternatively we could assume that the unemployed receive an old age welfare benefit as well. As long as this benefit is lower than the pension benefit our results do not change. Here we have implicitly assumed that the old age welfare benefit of the unemployed is embodied in the unemployment benefit. Since consumers are not credit constraint this implicit assumption does not affect the household maximization problem.
} 
household, and we ignore the underlying structure of the pension program until we discuss the constraint of the government.

The income of each consumer is spent either on consumption when young or can be saved for consumption during retirement. We have assumed that the price of consumption good is constant, since the small open economy faces an infinitely elastic foreign excess supply of the good, so we can normalize it to unity. Consumers born at $t$ can save either by purchasing stocks $\theta_{t+1}$, at the price $\mathrm{q}_{\mathrm{t}}$ or by purchasing (nondepreciated) physical capital $\mathrm{K}_{\mathrm{t}+1}$, at the price of 1 . There is perfect foresight regarding all future returns and prices, and there are no imperfections in the capital and in the stock market. At retirement, consumers consume the income generated by their savings, which is equal to the return to physical capital $(1+\mathrm{r}) \mathrm{K}_{\mathrm{t}+1}$ plus the return to stocks $\left(d_{t+1}+q_{t+1}\right)$, with $d_{t+1}$ the dividend per stock.

If we define $l$ to be equal to 1 when the agent is employed at t, and zero otherwise, the budget constraint for each consumer is:

$$
\begin{aligned}
& c_{t}+K_{t+1}+q_{t} \theta_{t+1}=l w_{t}(1-\tau)+(1-l) b \bar{w}_{t} \\
& c_{t+1}=(1+r) K_{t+1}+\left(d_{t+1}+q_{t+1}\right) \theta_{t+1}+l P_{t+1}
\end{aligned}
$$

The maximization of (1) subject to (2) and (3) yields first period consumption and savings:

$$
\begin{gathered}
c_{t}=\delta\left[l\left(w_{t}(1-\tau)+\frac{P_{t+1}}{1+r}\right)+(1-l) b \bar{w}_{t}\right] \\
S_{t}=K_{t+1}+q_{t} \theta_{t+1}=(1-\delta)\left[l\left(w_{t}(1-\tau)-\frac{P_{t+1}}{1+r}\right)+(1-l) b \bar{w}_{t}\right]
\end{gathered}
$$




\section{Firms}

There is a large number of perfectly competitive firms that produce a homogeneous good that may be consumed or stored to be used as capital in the next period. For simplicity and in order to avoid the additional notation, we normalize the number of firms to 1. The production function of the representative firm exhibits decreasing returns to scale ${ }^{4}$, and for simplicity we assume that it has the form:

$$
Y_{t}=A_{t} K_{t}^{\gamma} L_{t}^{\beta}
$$

where $\beta+\gamma<1$, and $A_{t}$ is the state of technology at time $t$, which is assumed to grow at a constant rate g, i.e. $A_{t}=(1+i) A_{t+1}$.

All firm decisions are made by the owners of the firm, i.e. the stock holders. Given that we do not allow for bequests in the economy, at each time period all stocks are owned by the members of the old generation. Since the members of the old generation do not have any labour endowment, the firm owners cannot at the same time be the workers of the firm.

Firm profits are distributed as dividends to the stock owners. Stocks are traded in the stock market, with no transactions cost. All traders are assumed to be small relative to the market and to share perfect and complete information. The above assumptions imply that the prices of the stocks are equal to the stream of all expected future dividends and that the value of the firm will be equal to the product of total stocks outstanding times the price of each stock. For simplicity we normalize the number of stocks of each firm to unity. If we define $\pi_{\mathrm{t}}$ as profits in period $\mathrm{t}$, i.e.:

$$
\pi_{t}=K_{t}^{\gamma} L_{t}^{\beta}-w_{t} L_{t}-r K_{t}
$$

then the value of each firm is given by:

\footnotetext{
${ }^{4}$ Due to the decreasing returns to scale technology, in equilibrium each firm makes positive profits, which are split between the workers and the owners of the firm through bargaining. With no profits the bargaining between workers and firm owners has no meaning as there is nothing to split among workers and firm owners.
} 


$$
\Pi(t)=\pi_{t}+\sum_{i=1}^{\infty} \frac{\pi_{t+i}}{(1+r)^{i}}
$$

The firm owners in order to maximize their income, and thus their utility, they want to maximize the return to stocks, i.e. the dividend per stock plus stock's selling price divided by the price they bought the stock. As we argued above this is equivalent to maximizing the stream of all future profits and thus the stock market value of the firm:

$$
\max \Pi(t)=\pi_{t}+\sum_{i=1}^{\infty} \frac{\pi_{t+i}}{(1+r)^{i}}
$$

\section{Government}

The government levies a proportional tax on labour income, $\tau$. Tax revenues then finance two separate social security programs: unemployment and old- age pension benefit. In order to simplify the dynamics of the system we assume that each program runs in balance in each time period, and the government cannot transfer resources from the unemployment to the pension benefit program and vice versa.

The unemployment insurance program redistributes income from the employed to the unemployed. Then if $\mathrm{b}$ is the fixed percentage of the current period wage that is paid to the unemployed, i.e. the unemployment benefit replacement ratio and $\xi$ is the component of the tax rate $\tau$ that is used to finance the unemployment benefit program, the balanced budget requirement for the unemployment program is given by:

$$
\xi \bar{w}\left(1-u_{t}\right) N_{t}=b \bar{w}_{t} u_{t} N_{t}
$$

where $u_{t}$ is the unemployment rate at time $t$ and $\bar{w}_{t}$ is the average wage at $t$.

The second welfare program, i.e. the old- age pension benefit, accomplishes both intra- generational as well as inter- generational redistribution. For this reason we assume that the PAYGO pension benefit consists of two components: one part which is

directly related to individual contributions and a second part which pays a uniform benefit. Following Casamatta et. al. (2000) we define the former as the "Bismarckian" 
and the latter as the "Beveridgean" component. Moreover we define $\eta$ to be the "Bismarckian" factor, i.e. the fraction of the PAYGO benefit that is related to own contributions (Casamatta et. al., 2000).

Alongside the public- PAYGO pillar, there exists a private- funded pension pillar, with the pension benefit consisting of both these pillars. The funded pillar is fully contributory in the sense that each individual's contributions are invested in the capital market and when the worker retires he receives the compounded value of his contributions. Then if $\mathrm{f}$ is the share of the PAYGO component the pension benefit for each individual at $\mathrm{t}+1$ follows the rule:

$$
P_{t+1}=f B\left[(1-\eta) \bar{w}_{t}+\eta w_{t}\right]+(1-f) z w_{t}\left(1+r_{t+1}\right)
$$

where B is the PAYGO pension benefit replacement ratio and $\mathrm{z}$ the component of the labour tax rate that goes to the pension program. In what follows we use the words funding and privatization interchangeably in order to denote a reduction in $\mathrm{f}^{5}$.

By construction the funded pillar is always in balance, since each individual receives as a pension the future value of his contributions. Then pension program is run in balance if the PAYGO pillar is in balance, i.e. ${ }^{6}$ :

$$
f B \bar{w}_{t}\left(1-u_{t}\right) N_{t}=f z \bar{w}_{t+1}\left(1-u_{t+1}\right) N_{t+1}
$$

\section{Stock Market Equilibrium}

Since there is no uncertainty in the economy and no imperfections in the stock market, the return to stocks (dividend per share plus capital gain) will be equal to the

\footnotetext{
${ }^{5}$ A private system with partial or full funding, that works as forced savings- individual accounts system, would be equivalent in our setting to a funded system where pension benefits are determined by own contributions. The effects of increased funding that we examine in our model would go through even if the government manages the funded system.

${ }^{6}$ In equilibrium, since all firms and all workers are identical, each worker's wage rate will be equal to the average wage, i.e. $\bar{w}_{t}=w_{t}$, which implies that $(1-\eta) \bar{w}_{t}+\eta w_{t}=\bar{w}_{t}$ We exploit this fact when stating the budget constraint(12).
} 
return to physical capital. Then the capital market equilibrium will be determined by the following arbitrage condition:

$$
1+r_{t+1}=\frac{d_{t+1}+q_{t+1}}{q_{t}}
$$

\section{Labour Market Equilibrium}

We now turn to the equilibrium in the labour market. By assumption, the labour market is not competitive. In every firm there is a firm specific union that has the power to bargain with the owners of the firm. We assume that the firm and the union bargain over wages and then the firm unilaterally chooses the level of employment, i.e. we assume a Right-to-Manage model of bargaining ${ }^{7}$ (Manning, 1987, Pencavel, 1991). Moreover we assume that the firm chooses the amount of capital it wishes employ prior to the wage bargaining stage.

To summarize the above, the timing of the events is as follows: At the first stage the firm chooses the amount of capital it wishes to employ. Afterwards the firm and the union bargain over wages and finally the firm unilaterally chooses the level of employment. Given the timing of events we solve the model backwards in order to find the time- consistent solution (Grout, 1984). Under the assumption of the small open economy with perfect capital mobility, the interest rate is fixed, $r$ and the economy instantaneously reaches the steady state. Therefore we can drop all time subscripts and focus only on the steady state values of the variables. Furthermore capital availability is not constraint by domestic savings and then the way the pension program is financed does not affect the capital supply. Public pensions however affect the labour market and thus indirectly the productivity of capital and eventually the demand for capital.

\footnotetext{
${ }^{7}$ The results of the analysis remain exactly the same when assume alternative bargaining models, e.g. Efficient Contract bargaining, i.e. the firm and the union bargain over both wages and employment, or when we assume that the firm chooses the amount of capital after the wage bargaining.
} 
At the third stage of the game the firm, given $\mathrm{w}$ and $\mathrm{K}$ (as determined at the previous stages), chooses the employment level that maximizes its profits. Maximization of (8) with respect to $L^{8}$ results into:

$$
w=\beta A K^{\gamma} L^{\beta-1}
$$

When the firm unilaterally chooses employment it equates the marginal productivity of labour with the wage rate. The solution to the bargaining problem (second stage) must always be consistent with(14).

In each firm there exists a firm specific union, thus the number of unions in the economy is equal to the number of firms. The representative union maximizes the expected life-time income of its members ${ }^{9}$. Employed union members earn net of taxes wage income plus the pension benefit at retirement. The unemployed members are free to join another union and seek employment in another firm. If they cannot find a job, they remain unemployed and receive the unemployment compensation. Then a representative union has the objective function:

$$
V=L\left[w(1-\tau)+\frac{P}{1+r}\right]+(N-L) x
$$

where $\mathrm{V}$ is the utility of the union, $\mathrm{L}$ is the number of employed members and $\mathrm{N}$ is the number of employees assigned to each firm ${ }^{10}$ and $\mathrm{x}$ is the expected income of the unemployed members. Following Layard et. al. (1991) we define $\mathrm{x}$ to be:

$$
x=(1-u)\left[\bar{w}(1-\tau)+\frac{P}{1+r}\right]+u b \bar{w}
$$

\footnotetext{
${ }^{8}$ Since there is no adjustment cost to capital and labour, (labour and capital market) outcomes at $t$ do not affect the stream of profits from $t$ onwards. Consequently firm decisions at $t$ will be independent of the future (or past) decisions.

${ }^{9}$ Given that the Cobb Douglas utility function produces an indirect utility function which is a linear function of the individual's income, utility and income maximization as goals of the union coincide.

${ }^{10}$ Since we have normalized the number of firms to 1 .
} 
Definition (16) states that workers expect with probability equal to $1-\mathrm{u}$ to find a job in another firm and earn the expected (average) wage. With probability u they expect to remain unemployed and receive the unemployment benefit ${ }^{11}$.

If an agreement is not reached all union members expect to earn $\mathrm{x}$. Then the fallback income if an agreement is not reached is ${ }^{12}$ :

$$
\bar{V}=N x
$$

Firms' objective is to maximize the present value of their profits. Each firm is allowed only to hire the workers of its union ${ }^{13}$. By the assumption that the capital choice is made prior to bargaining, the firm has rented the capital and if an agreement is not reached it still has to pay the rental rate to the capital owners. However, the inability to reach an agreement at $t$ does not affect the path of capital and the structure of the bargaining in the subsequent periods ${ }^{14}$. Given the above, the objective of the firm is to maximize the difference

$$
\Pi-\bar{\Pi}=K^{\gamma} L^{\beta}-w L
$$

where $\bar{\Pi}$ is the profits of the firm if an agreement with the union is not reached ${ }^{15}$.

Assuming a Nash bargaining solution ${ }^{16}$, the wage is obtained by maximizing:

\footnotetext{
${ }^{11}$ Alternative we can motivate (15), as if all workers have a unit endowment of labour and only (1-u) of their endowment is employed whereas $u$ of their unit endowment is unemployed (Summers, 1988, provides a similar explanation in an efficiency wage model of unemployment). According to this assumption, the pension benefit is reduced according to the duration of the unemployment spell, whereas during unemployment instead of the wage rate the workers earn the unemployment benefit.

${ }^{12}$ The fallback position of workers as specified in (16) is completely proportional to the wage rate. Even if we specify a non- proportional to the wage rate outside option, e.g. an unemployment benefit which is not indexed on wages, nothing would change in our analysis.

${ }^{13}$ By assumption, there is a union attached to each firm. For a worker to move to another firm (if there is a job opening in that firm), he must join its union.

${ }^{14}$ This rests on the fact that there is no adjustment cost on capital (see Devereux and Lockwood, 1991)

${ }^{15}$ The difference between the profits at $\mathrm{t}$ and the fallback profits at $\mathrm{t}$ are in fact:

$\Pi(t)-\bar{\Pi}(t)=\left(K_{t}^{\gamma} L_{t}^{\beta}-w_{t} L_{t}-r_{t} K_{t}+\sum_{i=1}^{\infty} \frac{\pi_{t+i}}{(1+r)^{i}}\right)-\left(-r_{t} K_{t}+\sum_{i=1}^{\infty} \frac{\pi_{t+i}}{(1+r)^{i}}\right)=K_{t}^{\gamma} L_{t}^{\beta}-w_{t} L_{t}$, with the last equality derived from the fact that the profits from $t+1$ onwards do not depend on the outcome of the bargaining at $\mathrm{t}$.

${ }^{16}$ It is known that a non- cooperative interpretation of the bargaining problem is compatible with Nash's solution. For example Binmore, Rubinstein and Wolinsky (1986) have demonstrated that the perfect equilibrium of the strategic two -person bargaining game can converge to the Nash's solution.
} 


$$
\max _{w} \Omega=\left(K^{\gamma} L^{\beta}-w L\right)^{a}\left[L\left[w(1-\tau)+\frac{P}{1+r}-x\right]\right]^{1-a},
$$

where $0<\alpha<1$ is the relative bargaining strength of the firm.

Maximizing (19) subject to (14) gives the first order condition:

$$
\left(\frac{w(1-\tau)+\frac{P}{1+r}-x}{w}\right)=\frac{(1-\alpha)(1-\beta)\left(1-f z-\xi+\frac{f \eta B}{1+r}\right)}{(1-a+\alpha \beta)}
$$

In equilibrium, because workers have the same ability and all firms produce under the same technology it follows that $w=\bar{w}$. In that case equation (20) can be solved for the equilibrium unemployment rate:

$$
u=\frac{N-L}{N}=\frac{(1-\alpha)(1-\beta)\left(1-f z-\xi+\frac{f \eta B}{1+r}\right)}{(1-a+\alpha \beta)\left(1-f z-\xi+\frac{f B}{1+r}-b\right)}
$$

Equilibrium unemployment depends on the policy parameters $(z, \xi, f, b, B, \eta)$ as well as the relative power of unions in the bargaining, 1- $\alpha$ and the share of labour in the production, $\beta$. This a quite standard solution of the unemployment rate in a union model (as for example in Layard et.al., 1991, Hart and Moutos, 1995).

Parameter B enters directly on the expression for $u$. The intuition behind the result is very simple; an increase on the pension replacement ratio, $\mathrm{B}$, raises the workers expected income at retirement. This increase in the retirement income is received by the workers only if they were employed when young. Then workers have an incentive to show wage moderation, in order to reap the benefits of higher B at retirement, which in turns reduces unemployment.

This latter effect depends crucially on the structure of the pension system, i.e. the degree that the public pension is directly related to the individual earning, $\eta$, and on the relative size of the PAYGO pension component, f. For example when $\eta$ is low, then the 
pension benefit has a higher (positive) effect on $u$. An increase in w increases the pension benefit only by $\eta$, while it increases the risk of unemployment and reduces the probability of receiving the pension benefit at retirement. With a lower value of $\eta$, the

incentives for wage moderation are less strong. The same rationale applies when $\mathrm{f}$ changes, since in the funded pension system $(\mathrm{f}=0)$, benefits depend only on own contributions.

The above rely on a partial equilibrium intuition; an increase in B comes from a (permanent) increase on taxes, $\mathrm{z}$, and pension contributions also affect the unemployment rate. Moreover $\mathrm{f}$ also affects the unemployment rate through the reduction in the implicit labour tax. We explore this issue more in the next section where we consider the general equilibrium effects of a change in $\mathrm{f}$.

\section{Capital market equilibrium}

Before the wage bargaining and the labour employment decision, the firm chooses the amount of capital it rents from the capital owners (i.e. old age agents). Profits of the firm, taking $\mathrm{L}$ and $\mathrm{w}$ as given from equation (14), can be written $\mathrm{as}^{17}$ :

$$
\pi=(1-\beta) A K^{\gamma} L^{\beta}-r K
$$

The value of $\mathrm{K}$ that gives the maximum profits is the one that equates the return to capital with the marginal productivity of capital:

$$
r=\gamma(1-\beta) A K^{\gamma-1} L^{\beta}
$$

With capital determined by (23) and the wage and employment determined by (14) and (21) we can compute total dividends per firm:

$$
d=A K^{\gamma} L^{\beta}-w L-r K=(1-\gamma)(1-\beta) A K^{\gamma} L^{\beta}
$$

\footnotetext{
${ }^{17}$ The objective of the firm is to maximize the present value of all future profits. The future stream of profits however do not depend on the capital chosen today, so without loss of generality we drop from (22) the present value of all future profits.
} 
From equations(13),(23) and (24) we obtain the (steady state) price of stocks q as:

$$
q=\frac{d}{r}=\frac{1-\gamma}{\gamma} K
$$

Finally we can compute the returns to the PAYGO benefit from(12). Equation (21) shows that unemployment is constant and depends on the policy parameters and $\alpha, \beta$. Then the rate of growth of employment, L will be equal to the rate of growth of population, n. Further, since productivity grows at a constant rate i, the growth factor of wages will be equal to $(1+g)=(1+n)^{\frac{\beta+\gamma-1}{1-\gamma}}(1+i)^{\frac{1}{1-\gamma}}$, due to the decreasing returns to scale technology. Therefore the budget constraint of the public pension program in the steady state equilibrium is:

$$
B=z \frac{w_{t+1} L_{t+1}}{w_{t} L_{t}}=z(1+g)(1+n)
$$

Equations (10), (14),(21), (23) and (26) determine the equilibrium L ,K, w, b,z. The price of stocks and the dividends are then residually determined by (24) and (25).

\section{Macroeconomic Effects of Funding}

We start by analyzing the effects of increased funding, i.e. reduction in $f$, on the macroeconomic equilibrium of the economy and then study the possibility of a Pareto improving transition to a funded system. We will deal with the latter issue, in section 4. In the present section we examine the effect of a reduction in $\mathrm{f}$ on labour and capital employment and wages.

A change in $\mathrm{f}$ affects the macroeconomic equilibrium through two channels. First, as long as the economy is dynamically efficient, i.e. the rate of growth of the economy is less than the interest rate, a reduction in f results in a reduction in the implicit tax rate 
on labour. Second, a reduction in $\mathrm{f}$ reduces the PAYGO component of the pension benefit and given $\eta$, it reduces the non- contributory part of the PAYGO pillar and limits the incentives for wage moderation. The following equations show the effects of a change in $\mathrm{f}$ on the unemployment rate, the demand for capital, the unemployment benefit replacement ratio and the wage rate:

$$
\begin{gathered}
\frac{d u}{d f}=z \bar{u} \Phi \\
\frac{d K}{d f}=\frac{-z \bar{u} \beta \Phi}{(1-\gamma)(1-\bar{u}) \frac{r}{\bar{K}}} \\
\frac{d b}{d f}=-(\bar{b}+\xi) z \Phi, \\
\frac{d w}{d f}=\frac{z \bar{u} \bar{w}(1-\beta-\gamma) \Phi}{(1-\bar{u})(1-\gamma)} \\
{\left[b\left(1-\eta \frac{(1+g)(1+n)}{1+r}\right)-\frac{(1+g)(1+n)}{1+r}(1-\eta)(1-\xi)\right]} \\
\left(1-f z+\frac{f z(1+g)(1+n)}{1+r}\right)\left(1-f z-\xi+\frac{\eta f z(1+g)(1+n)}{1+r}\right)
\end{gathered}
$$

and the bars above variables demote the baseline equilibrium values of these variables.

The above comparative static results depend only on the sign of $\Phi$. The denominator $\Phi$ is always positive, since in general $\tau=\mathrm{Z}+\xi<1$. Then the sign of $\Phi$ depends only on the sign of its numerator, which is ambiguous, i.e.:

$$
b\left(1-\eta \frac{(1+g)(1+n)}{1+r}\right)-\frac{(1+g)(1+n)}{1+r}(1-\eta)(1-\xi) \geq /<0
$$

Expression (32) can be either positive or negative depending on the underlying parameters values, since there are two forces at play: the implicit tax effect and the wage moderating- redistributive effect. The former effect can be either positive or negative depending on whether the economy is dynamically efficient. In a dynamically 
inefficient economy, the return to the PAYGO system is higher than the returns to the capital market. The pension benefit is higher than the present value of the contributions of the workers. In the dynamic inefficient economy, the PAYGO pension constitutes an implicit subsidy for the employed. On the other hand in a dynamically efficient economy, the return to the PAYGO system is lower than the returns to the capital market. The mandatory participation to the PAYGO system then entails an implicit tax on labour income, which increases unemployment.

The wage moderating effect on the other hand works always in the same way; given $\eta$, an increase in $\mathrm{f}$ increases the share of the non- contributory part of the pension ${ }^{18}$. Subsequently at the bargaining stage, with a higher $f$, wage increases translate into higher unemployment probability but leave the retirement income unaffected. Workers then have then an incentive to show wage moderation, which ultimately results into lower unemployment.

In a dynamically inefficient economy, both effects work towards the same direction and (32) is always negative; higher $\mathrm{f}$ results into lower unemployment. In a dynamically efficient economy, i.e. when the rate of population and economic growth is lower than the interest rate, (32) can take either sign; higher f may be unemployment reducing or unemployment creating. The overall effect depends on the value of $\eta$. With $\eta$ equal to one (fully "Bismarckian" system), (32) is always positive; when the PAYGO pension does not have a non- contributory- redistributive component then the wage moderating effect does not exist. A drop in $\mathrm{f}$ (i.e. increased funding) reduces unemployment since the implicit tax on labour falls. On the other hand if the PAYGO

\footnotetext{
${ }^{18}$ Given the fact that the fully funded system is fully contributory and that $\eta<1$.
} 
pension benefit is fully "Beveridgean" then the pension will be independent of the size of contributions, and (32) is more likely to be negative ${ }^{19}$.

To summarize the above results:

$$
\begin{aligned}
& \text { If } b\left(1-\eta \frac{(1+g)(1+n)}{1+r}\right)-\frac{(1+g)(1+n)}{1+r}(1-\eta)(1-\xi)>0 \\
& \Rightarrow \frac{d u}{d f}>0, \frac{d K}{d f}<0, \frac{d b}{d f}<0, \frac{d w}{d f}>0
\end{aligned},
$$

and vice versa.

\section{Can Pension Funding Increase the Welfare of the Population ${ }^{20}$ ?}

In the previous section we have examined the effects of funding on the macroeconomic variables. This section explains how the welfare of the population is affected by a change in $\mathrm{f}$. Welfare effects are derived from the expected indirect utility $^{21}$. From the Cobb- Douglas utility function and the solution for $c_{t}$ and $c_{t+1}$ as well as the budget constraint of the unemployment compensation program (10) and the constraint of the pension program (26) the expected indirect utility of the representative agent can be expressed as:

$$
W=\kappa w L\left(1-f z+\frac{f z(1+g)(1+n)}{(1+r)}\right)
$$

\footnotetext{
${ }^{19}$ Of course b must be less than $1-\xi$ otherwise all agents in the economy would prefer to be unemployed and earn more than the employed.

${ }^{20}$ Since the question of a Pareto improving transition to a funded system is relevant only when the economy is dynamically efficient, from this point onwards we assume that the interest rate is greater than the growth rate of the economy.

${ }^{21}$ The welfare effects of funding are considered with respect to the expected utility of the young. This was done in order to have a homogeneous (at least ex ante, before the employment status has been revealed) population. If the population is divided into two groups, employed and unemployed, then a privatization policy may be difficult to construct (see Brunner, 1996 for the relevant discussion). Implicitly the model however allows us to use the expected utility in order to make welfare comparisons and at the same time be able to derive the welfare effects of privatization. The way we model unemployment is as if all workers remain unemployed for $\mathrm{u}$ of their time (see also footnote 8). Their pension benefit then is reduced according to the length of unemployment.
} 
where $\kappa=\delta^{\delta}[(1-\delta)(1+r)]^{1-\delta}$. Since the utility function is Cobb- Douglas, the indirect utility is a linear function on life- time income, i.e. $\mathrm{W}=\kappa \mathrm{I}$, where $\mathrm{I}$ is the life- time income of the young, $I=w L\left(1-f z+\frac{f z(1+g)(1+n)}{(1+r)}\right)$.

One can now easily derive the effects of a change in $f$ on the welfare of the young:

$$
\frac{d W}{d f}=\kappa \bar{L} \bar{w} z\left[\frac{-\Phi\left(1-f z+\frac{f z(1+g)(1+n)}{1+r}\right)\left(\frac{\beta+\beta(1-\gamma) r}{(1-\gamma) r}\right)}{(1-u)}-\frac{(1+r)-(1+g)(1+n)}{1+r}\right]
$$

Clearly the expected welfare of the young generation is a negative function of $\mathrm{f}$ when (32) holds; pension funding (lower f), results into lower unemployment and higher welfare for the young agents. However if (32) is negative then a reduction in $\mathrm{f}$ has ambiguous effects. On the one hand if (32) is positive the first term inside the square brackets in (36) would be positive, whereas the second term negative. The first term corresponds to the (negative) effect of the increased unemployment on household welfare, whereas the second effect corresponds to the (positive) effect on welfare of the lower implicit tax rate on consumption ${ }^{22}$.

If a transition to a funded system is initiated at time $\mathrm{T}_{0}$, the effect to the welfare of the young may be either positive or negative as (35) reveals. On the other hand at time $\mathrm{T}_{0}$ there are old agents alive, and the reduction in the PAYGO pillar would result into lower welfare for them. If at time $\mathrm{T}_{0}$ we have a change on the benefit structure such that $\mathrm{df}<0$, where $\mathrm{df}$ is the change in $\mathrm{f}$, then the pension benefits of the retirees would

\footnotetext{
${ }^{22}$ In contrast to Demmel and Keuschnigg (2000) and Corneo and Marquardt (2000) the reform is not always Pareto superior to the status- quo. This is because the public PAYGO system may create incentives for wage moderation that outweigh the negative effect of the pension contributions- tax on employment
} 
decreased by zwLdf. If (35) is positive ${ }^{23}$, increased funding reduces the welfare of the young and then a transition to a funded system will always decrease the welfare of the young as well as the old individuals. If (35) however is negative can we design a transition to a funded system that compensates the old at $\mathrm{T}_{0}$ for their loss in pension income and still make the young and all future generations better off?

To answer this question we follow the strategy of Verbon (1988) and van Groezen et. al. (2003) and assume that in order to compensate the old, the government issues public debt equal to $\Delta_{0}$ in order to finance the pensions of the current retirees. To simplify things we assume that prior to $\mathrm{T}_{0}$, the government debt is zero. Then the public debt at $\mathrm{T}_{0}$ is $\Delta_{0}=-(z w L) d f^{24}$. To finance the debt the government imposes taxes on the income of the young, either employed or unemployed, with a tax rate $\mu^{25}$ until all debt has been repaid. Since the tax rate is uniform across young individuals, by the transformation invariance axiom that the Nash bargaining solution satisfies, the wage and the unemployment rate (and all other macroeconomic variables as we have derived them in section 2) are not affected by the introduction of $\mu$. After the whole debt has been repaid, $\mu$ becomes zero and thereafter the young generations can reap all the gains of privatization. The present value of total revenues of this tax then must be equal to:

$$
\mu L w \sum_{i=0}^{\infty} \frac{[(1+g)(1+n)]^{i}}{(1+r)^{i}}
$$

The intertemporal budget constraint of the government is satisfied if the present value of the revenue (37) is equal to the present value of the debt, i.e. $\mu$ is:

$$
\mu=-z \frac{(1+r)-(1+g)(1+n)}{(1+r)} d f
$$

\footnotetext{
${ }^{23}$ Lower f lower welfare for the young generation and all generations thereafter.

${ }^{24}$ We have the minus sign in $\Delta_{0}$ because increased funding corresponds to $\mathrm{df}<0$.

${ }^{25}$ The expected utility of the young generation is not affected by the introduction of $\mu$ only if the cost of the reform is born by the entire young generation (employed and unemployed), and not by the employed only.
} 
The above transition scheme allows for a Pareto improvement if the gain in the expected worker income ${ }^{26}$ is higher than the taxes needed to finance the debt, i.e.:

$$
\left[\frac{\Phi\left(1-f z+\frac{f z(1+g)(1+n)}{1+r}\right)\left(\frac{\beta+\beta(1-\gamma) r}{(1-\gamma) r}\right)}{(1-u)}+\frac{(1+r)-(1+g)(1+n)}{1+r}\right]>\frac{(1+r)-(1+g)(1+n)}{(1+r)}
$$

If $\Phi=0$, i.e. there are no employment effects of a change in $f$, then (39) is satisfied with equality. The present value of all the welfare gains of the increased funding is equal to the transition cost. When pension funding does not affect employment, then privatization only transforms an implicit debt to an explicit one (Homburg, 1990, Sinn, 2000). The model then collapses to the case highlighted by Verbon (1988) and Breyer (1989) and the PAYGO benefit reduction cannot be Pareto improving.

However if $\Phi>0$, then pension funding as described here can make some generations better off without hurting all other generations. Then the reform is Pareto improving if the private system entails lower unemployment than the PAYGO system, i.e. if the expression in equation (33) is positive.

A final case arises when $\Phi<0$ but however the left hand side of (39) is positive ${ }^{27}$. In this case privatizing the pension scheme may be welfare improving for the current young and all future generations, however when we take into account the transition cost, the cost of privatization is higher than the benefits.

Although we were able to derive analytical expression about the effects of pension funding on the macroeconomic equilibrium and welfare in the economy, the results depend upon the underlying parameter values. In order to access the empirical validity

\footnotetext{
${ }^{26}$ The change in workers expected income from a change in $\mathrm{f}$ is given by (35) by dropping $\kappa$, due to the linearity on income of the indirect utility function.

${ }^{27}$ Obviously in the case where $\Phi<0$ and the left hand side of (39) is negative has no meaning since in this case the reform makes no generation better- off.
} 
of our argument we experimented with various empirically plausible parameter values in order to examine the properties of the model.

With the exception of $f, \eta, r, i$ and $n$, our main results are robust with respect to the other underlying parameter values. For this reason we chose to report our results by changing the values of the above four variables. The rest of the parameter values chosen are: $\beta=0.75, \gamma=0.2, \alpha=0.75, \xi=0.02, \mathrm{z}=0.3, \mathrm{~N}=1, \mathrm{~A}=1$. These values guarantee that the calibrated model's features are similar to actual economies ${ }^{28}$ (e.g. the unemployment rate is between $8 \%$ and $10 \%$ ).

In the following figure we also fix $\mathrm{f}$ to be equal to 1 , i.e. a pure PAYGO system is in place. We plot three different cases, $\eta=0.1$ (dashed line), $\eta=0.5$ (solid line), $\eta=1$ (dotted line). Then each line in figure 1 is the locus of annual ${ }^{29}$ interest rate $r$ and economy growth rate g, for which (39) holds with equality, i.e. the reform is Pareto indifferent. Then below (above) the line, increased funding via a reduction in $\mathrm{f}$ entails net loses (gains).

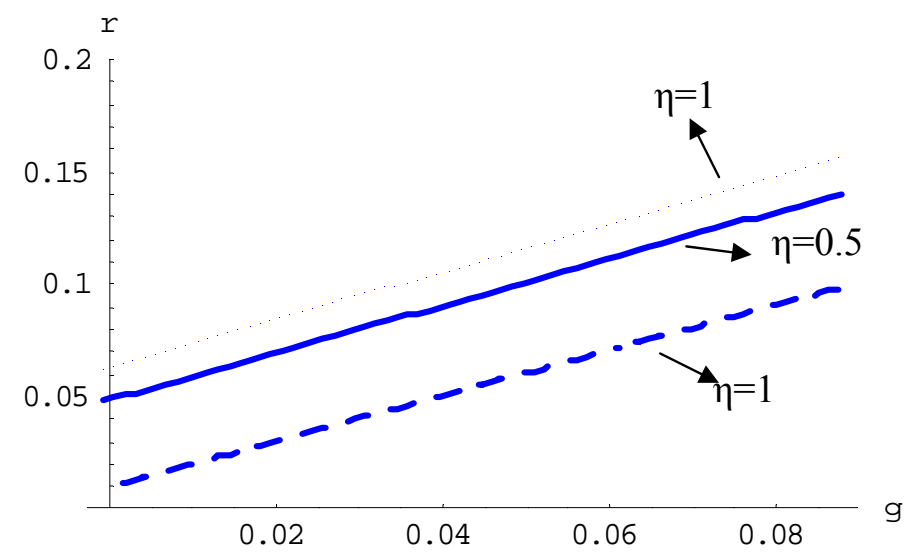

Figure 1: Combinations of $r$ and $g$, for which the reform is Pareto indifferent

\footnotetext{
${ }^{28}$ We couldn't replicate the real values for the unemployment benefit replacement ratio $b$. In order to have b close to $50 \%$, $\xi$ should have been $20 \%$. However in this case the unemployment rate was higher than $26 \%$.

${ }^{29}$ Since we have a two period overlapping generation model, we assume that each period lasts for 30 years, and the interest rate and the growth rate correspond to 30 year compounded rates. Here we translate these rates into annual rates.
} 
For example when $\eta=0.5$ (solid line) and the annual growth rate,g, is zero, then a Pareto improving transition to a funded system is possible if the interest rate is higher than $5 \%$. When the annual rate of growth is around $2.5 \%$, the corresponding interest rate must be at least $7.5 \%$. For a given level of $g$ the critical value of $r$ increases (decreases) the higher is $\eta$.

\section{Conclusions}

The main purpose of this paper has been to show that in a second best environment with unemployment, a public pension system can be welfare superior to a private system even if the economy is dynamically efficient.

Our finding about the effect of the pension system on the unemployment rate identified in this paper can be given an alternative and possibly broader interpretation. From the literature on taxation in unionized economies we know that increased tax progressivity leads to lower wage demands as wage increases are less valuable, generating in this way more employment (Koskela and Vilmunen, 1996, Nickell, 2003). With some sleight of hand we can think of the pension benefit as a tax exemption, since some part of the taxes paid by the workers is returned as a pension benefit. In this interpretation a lower value of $\eta$ and/ or a higher value of $\mathrm{f}$ actually imply higher degrees of tax progression. According to this line of reasoning, countries that have adopted in the past a more progressive and thus more redistributive social security system may find it more difficult to slip back to a less redistributive (lower f), yet financially viable, system due to the perverse consequences that this change may have on the unemployment rate. 


\section{References}

Binmore, K., Rubinstein A., and Wolinsky A., 1986. The Nash bargaining solution in economic modeling, Rand Journal of Economics 17, 176- 188.

Breyer, F., 1989. On the intergenerational Pareto efficiency of pay- as- you- go financed schemes. Journal of Institutional and Theoretical Economics 145, 643-658.

Brunner, J. K., 1996. Transition from a pay-as- you go to a fully funded pension system: the case of differing individuals and intragenerational fairness. Journal of Public Economics 60, 131-146.

Casamatta, G., Cremer H., and Pestieau P., 2000. The political economy of Social Security, Scandinavian Journal of Economics 102, 502-522.

Corneo, G. and Marquardt, M., 2000. Public pension, unemployment insurance and growth. Journal of Public Economics 75, 293-311.

Demmel, R. and Keuschnigg, C., 2000. Funded pensions and unemployment. FinanzArchiv 57, 22-38.

Devereux, M. B. and Lockwood, B., 1991. Trade unions, non- binding wage agreements and capital accumulation. European Economic Review 35, 1411-1427.

Diamond, P.A, 1996. Proposals to restructure Social Security, Journal of Economic Perspectives 10, 67-88.

Feldstein, M. and Liebman, J. B., 2002. Social security. In: Auerbach A.J. and Feldstein, M. (Eds.), Handbook of Public Economics. Elsevier Science, Amsterdam.

Gramlich, E.M., 1996. Different approaches for dealing with Social Security, Journal of Economic Perspectives 10, 55-66.

Grout, P., 1984. Investment and wages in the absence of legally binding contracts: a Nash bargaining approach. Econometrica 52, 449-460. 
Hart R., and Moutos, T., 1995. Human capital, employment and bargaining, Cambridge, Cambridge University Press.

Holzmann, R., 1997. Pension reform, financial market development and economic growth: preliminary evidence from Chile, IMF Staff Papers 44, 149-178.

Homburg, S., 1990. The efficiency of unfunded pension schemes. Journal of Institutional and Theoretical Economics 146, 640- 647.

Koskela, E., and Vilmunen, J, 1996. Tax Progression is good for employment in popular models of trade union behaviour, Labour Economics 3, 65-80.

Layard, R., Jackman, R., and Nickell, S., 1991. Unemployment, Oxford: Oxford University Press.

Manning, A., 1987. An integration of trade union models in a sequential bargaining framework, Economic Journal 97, 121-139.

Nickell, S., 2003. Employment and Taxes, CESifo Discussion Paper No 1109.

Pencavel, J., 1991. Labour markets under trade unionism: employment, wages and hours, Oxford: Blackwell.

Summers, L. H., 1988. Relative wages, efficiency wages, and Keynesian unemployment, American Economic Review 78, 383-385.

van Groezen, B., Leers, T. and Meijdam L., 2003. Social security and endogenous fertility: pensions and child allowances as Siamese twins. Journal of Public Economics 87, 233-251.

Verbon, H. A. A., 1988. Conversion policies for public pensions plans in a small open economy. In: Gustafsson, B., Klevmarken, N. A. (Eds), The Political Economy of Social Security. Elsevier Science, Amsterdam.

Sinn, H.W., 2000. Why a funded pension and why it is not useful. International Tax and Public Finance 7, 389- 410. 
World Bank, 1994. Averting the old age crisis. Washington, D.C.: World Bank. 